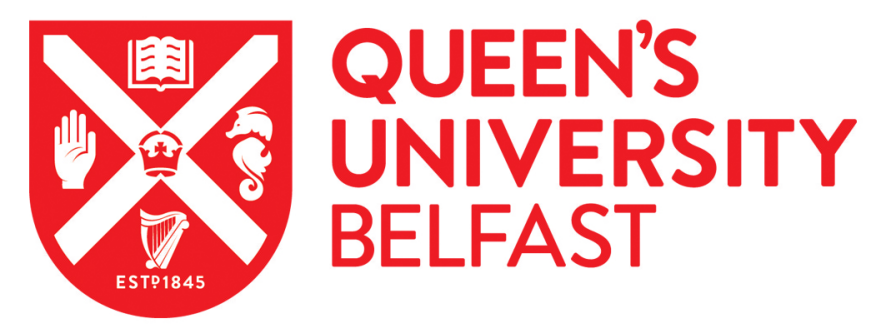

\title{
Informants' ratings of activity level in infancy predict ADHD symptoms and diagnoses in childhood
}

\author{
Meeuwsen, M., Perra, O., van Goozen, S. H. M., \& Hay, D. F. (2018). Informants' ratings of activity level in \\ infancy predict ADHD symptoms and diagnoses in childhood. Development and Psychopathology, [15]. \\ https://doi.org/10.1017/S0954579418000597
}

\section{Published in:}

Development and Psychopathology

\section{Document Version:}

Peer reviewed version

Queen's University Belfast - Research Portal:

Link to publication record in Queen's University Belfast Research Portal

\section{Publisher rights}

(C) 2018 Cambridge University Press.

This work is made available online in accordance with the publisher's policies. Please refer to any applicable terms of use of the publisher.

\section{General rights}

Copyright for the publications made accessible via the Queen's University Belfast Research Portal is retained by the author(s) and / or other copyright owners and it is a condition of accessing these publications that users recognise and abide by the legal requirements associated with these rights.

Take down policy

The Research Portal is Queen's institutional repository that provides access to Queen's research output. Every effort has been made to ensure that content in the Research Portal does not infringe any person's rights, or applicable UK laws. If you discover content in the Research Portal that you believe breaches copyright or violates any law, please contact openaccess@qub.ac.uk. 
Infant Activity Level and ADHD

Informants' Ratings of Activity Level in Infancy Predict ADHD Symptoms and Diagnoses in Childhood

Mirjam Meeuwsen, Oliver Perra, Stephanie H M van Goozen, Dale F Hay, 
Infant Activity Level and ADHD

\begin{abstract}
We tested the hypothesis that high activity levels in infancy would predict selfregulatory problems and later symptoms of ADHD in a longitudinal study of British families $(N=321)$. Infants' activity levels were assessed at 6 months, using three informants' reports from the Infant Behaviour Questionnaire (IBQ) and Actigraphs during baseline, attention and restraint tasks. At a mean of 33 months, the children were assessed on self-regulatory tasks and at a mean of 36 months three informants reported symptoms of ADHD. At a mean of 7.0 years, the children were assessed on executive function tasks; three informants reported on the child's symptoms of ADHD; and diagnoses of disorder were obtained using the Preschool Age Psychiatric Assessment (PAPA). Informants' reports of high activity levels at 6 months predicted ADHD symptoms in early childhood and diagnoses of ADHD with clinical impairment at age 7. The IBQ activity scale was also associated with the children's later performance on self-regulation tasks in early and middle childhood. Activity level in infancy reflects normal variation and is not a sign of psychopathology. However, these findings suggest that further study of the correlates of high activity level in infancy may help identify those children most at risk for disorder.
\end{abstract}




\section{Informants' Ratings of Activity Level in Infancy Predict Self-regulatory Deficits and ADHD Symptoms in Childhood}

Attention Deficit and Hyperactivity Disorder (ADHD) is a lifelong

neurodevelopmental disorder that can be identified in early childhood; it affects approximately 7\% of children (Thomas, Sanders, Doust, Beller, \& Glasziou, 2015).

Biological processes contribute to the etiology of ADHD: for example, numerous studies have demonstrated the importance of genetic influence on ADHD (see metaanalysis by Nikolas \& Burt, 2010) and many neuroimaging studies have identified brain regions associated with neurocognitive impairment in the context of ADHD (see meta-analysis by Cortese et al., 2012). However, such studies often focus on adults and older children. Knowledge about very early predictors of ADHD would further our understanding of its developmental origins of the disorder. In particular, it would be helpful to identify behavioral tendencies in infancy that appear to be precursors to later ADHD symptoms. Thus the main aim of this paper is to test the developmental hypothesis that high activity levels in infancy predict ADHD symptoms and associated self-regulatory deficits in early childhood, which in turn predict diagnoses of ADHD in middle childhood.

This hypothesis draws upon the theoretical perspective of developmental psychopathology (Sroufe \& Rutter, 1984), which sought to identify the developmental origins of childhood disorders. In setting out the agenda for the field, Sroufe and Rutter (1984) noted that "there should be equal concern with child pathology, its relation to non-disordered behavior, and with the origins of disordered behavior that does not appear in clinical form until adulthood" (p. 18). They argued that, in order to identify preclinical signs of disorders that emerge later in development, it was 
useful to conduct longitudinal research in samples in which some but not all infants would go on to develop full blown disorders. In keeping with that principle, we sought to examine links between activity level in infancy and subsequent ADHD symptoms in the context of a prospective longitudinal study of firstborn children in a representative community sample.

\section{The Search for Early Predictors of ADHD}

It is well established that ADHD can be reliably diagnosed in early childhood (e.g., Moreland \& Dumas, 2008) and several investigators have sought to identify infant characteristics that might predict later symptoms of ADHD. Two approaches have been taken to this topic: (1) studies of the temperaments of infants who are at familial risk for ADHD and (2) longitudinal studies of infant temperament that use ADHD as an outcome.

The first approach is exemplified by a study that assessed infants at familial risk and comparison infants during a home visit before 8 weeks of age, which identified state organization difficulties (irritability, state lability, and problems in self-quieting) in the at risk group (Auerbach et al., 2005). Negative emotionality and behavior during a still face paradigm have also been reported for infants at familial risk for ADHD (Sullivan et al., 2015).

The second approach is represented by longitudinal studies of infant temperament that predict symptoms of ADHD later in life (e.g., Galera et al., 2011; Becker et al., 2010; Olson, Bates, Sandy, \& Schilling, 2002). These longitudinal analyses have revealed a number of potential predictors of ADHD, including difficult temperament, negative affect, regulatory problems, and off-task disengagement. There are some indications of possible biomarkers, including genotype (Becker et al., 
2010). In one retrospective longitudinal study, it was observed that children with diagnoses of ADHD had previously shown a reduction in head growth in infancy (Gurevitz, Geva, Varon, \& Leitner, 2014).

This empirical literature reflects longstanding theoretical debates about the etiology of ADHD, in particular the relationship between dimensions of temperament and symptoms of ADHD (e.g., Nigg, 2001; Nigg, Goldsmith, \& Sachek, 2004).

Although both lines of empirical work on links between temperament and ADHD suggest that the first steps on the developmental pathway to ADHD are taken in infancy, it is not yet clear exactly when temperamental differences transmute into clinical symptoms; nor is it yet established which dimensions of temperament are the most potent predictors of later ADHD. To date, studies of links between infant temperament and ADHD have concentrated on emotion regulation (e.g., Sullivan et al., 2015) and the broader concept of 'difficult temperament' (e.g., Galera et al., 2010; Gurevitz et al., 2014). Therefore, to supplement the existing literature on temperamental precursors to ADHD, we focused on activity level as a behavior that shows normal variation in infancy but might later consolidate into a symptom of disorder for some individuals.

\section{Activity Level in Infancy and Later ADHD Symptoms}

Although ADHD is multidimensional and hyperactivity can be distinguished from other dimensions of ADHD (Taylor, 2009), many studies have shown that children with ADHD exhibit higher activity than comparison children in most situations (Dane, Schachar, \& Tannock, 2000; Porrino et al., 1983; Teicher, Ito, Glod, \& Barber, 1996;;; Wood, Asherton, Rijsdijk, \& Kunsti, 2009). However, high activity is not in itself a clinical symptom; activity level in the first year of life is thought to 
reflect normal variation in activity as a dimension of temperament and not a sign of disorder. Under what circumstances, then, would high activity level in early life represent the starting point on a trajectory toward disorder? It is important to take into account other dimensions of infants' behavior that might account for links between early activity levels and later symptoms of ADHD, in particular difficulties in selfregulation. Previous work has suggested that, in situations where there are few restrictions on children's behavior, it can be difficult to distinguish children with ADHD from typically developing comparison children (Barkley, 1998). It is therefore possible that it is the combination of high activity in infancy plus subsequent self-regulatory difficulties that predicts forward to ADHD symptoms in childhood. Thus in our longitudinal study, children whose activity levels had been assessed in infancy were then tested in very early childhood on ageappropriate self-regulation tasks.

However, before testing for links between activity level in infancy, selfregulatory difficulties and eventual symptoms of ADHD, it was necessary to reflect on different ways of measuring infants' activity levels. In the psychometric tradition, activity is seen as a dimension of individual temperament, distinct from other dimensions that tap into behavioral or emotional regulation. As a dimension of temperament, activity levels are assessed by parents and other informants who reflect on children's characteristic behavior over time (e.g., Rothbart, 1981). In contrast, in the experimental psychology tradition, physical activity is measured directly using actometers or actigraphs (e.g., Teicher et al, 1996). Past research demonstrates that parents' reports on the IBQ Activity Scale do not necessarily correlate with infants' directly measured motor activity (Eaton \& Dureski, 1986), especially for younger 
infants (Worobey, 2014). Studies of motor activity in children with ADHD find that directly measured activity levels do not necessarily correlate with performance on tasks that measure inattention or impulsivity (e.g., Reichenbach, Halperin, Sharma, \& Newcorn, 1992). Furthermore, gender differences in infants' activity levels are larger when activity is directly measured rather than reported on by parents (Campbell \& Eaton, 1999). To explore these methodological issues further, we drew on both informants' reports and direct assessments of both activity levels and self-regulation.

\section{Familial Risk in Relation to Activity Levels and Later Outcomes}

The longitudinal design makes it possible to examine the contribution of family risk factors, such as a parent's own history of neurodevelopmental problems, to the emergence of ADHD. Therefore we tested the hypothesis that activity levels in infancy might predict later symptoms of ADHD while also examining family history of ADHD, a well-established risk for children's own symptoms (Faraone et al., 1995). There is some evidence that infants at familial risk for ADHD might already have elevated activity levels. In one high risk design, infants with familial risk showed somewhat higher activity levels than other members of the sample, although the difference was not significant (Auerbach et al., 2005). By measuring familial risk, our design combines two strategies used in past research in developmental psychopathology and in studies of links between infant temperament and ADHD in particular: (1) the comparison of infants at familial risk for ADHD and (2) longitudinal prediction from variation in of infant characteristics. In the present study, mothers' and biological fathers' symptoms of ADHD were examined in relation to their infants' behavior in infancy, early childhood and middle childhood. 


\section{Hypotheses to Be Tested and Analytic Plan}

First, we tested whether the informant-rated and directly observed measures of activity level in infancy were correlated with each other and with informant-rated and directly observed measures of self-regulation in infancy. Secondly, we tested the hypothesis that activity levels in infancy predicted performance on self-regulation tasks in early childhood and symptoms of ADHD, as reported by three informants (mothers, fathers, and a third family member or friend) at a mean age of 36 months. Next, we tested the hypothesis that activity levels in infancy might predict performance on ADHD-relevant executive function tasks and ADHD symptoms, as rated by mothers, fathers, and teacher, at 7 years of age. We expected that any observed continuity might be mediated by the child's ADHD symptoms in early childhood. Finally, we tested whether activity levels in infancy predicted a clinically significant outcome, DSM diagnoses of ADHD with clinical impairment at 7 years.

\section{Method}

\section{Participants}

We tested these hypotheses in the Cardiff Child Development Study (CCDS). All procedures were approved by the Cardiff University School of Psychology Research Ethics Committee and the U.K. National Health Service (NHS) MultiCentre Research Ethics Committee. First-time pregnant women were recruited from prenatal clinics in hospitals and general practice clinics in two National Health Service (NHS) Trusts: Cardiff and Gwent, South Wales, and through a specialized midwifery team designed to support pregnant women at high social risk. All potential participants provided contact details and both those who chose to participate and those who chose not to participate in the study represented the entire range of 
socioeconomic categories associated with U.K. postal codes. The CCDS sample was found to be nationally representative on sociodemographic variables as shown by analyses that compared demographic characteristics of the CCDS sample with the subsample of firstborn children in the Millennium Cohort Study, the most recent national birth cohort study in the UK (K. Kiernan, personal communication, April 2009).

The only exclusion criteria set were an infant's death or illness too severe to permit assessment. Following initial recruitment, participants were followed up at mean ages of $6,12,21$, and 36 months and at 7 years. The current analyses focus on a sample of 321 participants who contributed data to the measures of activity in infancy, ADHD or regulation in toddlerhood, or ADHD at age 7. These represented $94 \%$ of the original cohort recruited at Wave 1 of the study (see Table 1 for demographic characteristics).

\section{Procedure}

During each wave of assessment, a mixture of interview, questionnaire and observational data were collected at home or at the School of Psychology, Cardiff University. Multiple informants completed questionnaires (mothers, fathers and a family member/friend who knew the child well at the infant and toddler assessments and teachers at the 7-year assessment). Families were compensated for travel expenses and offered gift vouchers as acknowledgement for their participation.

During pregnancy all mothers and $87 \%$ of the fathers completed questionnaires and were interviewed separately. At a mean of 6 months a two-hour home-visit consisted of a mother interview and a behavioral observation of the infant and mother (or primary caregiver). Parents and a third informant were asked to 
complete questionnaires. At a mean of 36 months, parents and a third informant were asked to complete questionnaires. Children and their primary caregivers were invited for a laboratory visit that incorporated individual testing as well as an assessment of peer interaction during a simulated birthday party. Self-regulatory tasks were administered during the individual testing. At a mean of 7.0 years, during two home visits, the primary caregiver was interviewed whilst a child tester administered a battery of age-appropriate tasks.

\section{Measures}

Sociodemographic adversity. Parents reported on sociodemographic variables during the pregnancy home visit. A general index of child's exposure to maternal factors known to be associated with risk for social adversity was created using Principal Component Analysis (PCA). The maternal experiences that contributed to this index were: (1) not having achieved basic educational attainments (i.e., the mother having no qualifications or fewer than five General Certificate of Secondary Education (GCSE) examinations passed or equivalent attainments); (2) being 19 years of age or under at the time of child's birth; (3) not being legally married during the pregnancy; (4) not being in a stable couple relationship during the pregnancy; and (5) the mother's occupation being classified as working class (as opposed to a middle class occupation) according to the Standard Occupational Classification 2000 (SOC2000; Elias, McKnight, \& Kinshott, 1999). All these items were categorical; therefore the PCA was based on the polychoric correlation matrix. The PCA confirmed that all these items contributed to a single component (eigenvalues 3.84 and 0.68 for the first and second component extracted, respectively); this component explained approximately $77 \%$ of the shared variance in 
these risk indicators. Summary scores derived from this PCA were used as a proxy for the family's exposure to socio-economic adversity. The subsample of 265 families who rated infants' activity levels at 6 months are slightly less exposed to adversity than the full sample recruited in pregnancy (Table 1), with a mean adversity factor score $=-.19$.

Familial risk for ADHD. Fathers and mothers completed a retrospective questionnaire during the antenatal assessment, which contained 5 items rated on a 3point scale that measured parental DSM-IV ADHD symptoms retrospectively ("I was restless and could not stay still for long," "I was constantly fidgeting or squirming," "I was easily distracted and found it difficult to concentrate," "I thought things out before acting on them" and "I saw tasks through to the end. My attention was good"). Missing items were prorated and for parents who had not completed the questionnaire, but had reported to the interviewer whether or not they had been diagnosed with $\mathrm{ADHD}$ as a child, a regression analysis was conducted to compute a predicted score. The internal consistency of this scale was comparable to other 5 -item scales, $\alpha=.70$ for mothers and $\alpha=.66$ for fathers. Mothers' $(M=3.53, S D 2.27)$ and fathers' $(M$ $=4.33, S D$ 2.19) scores were averaged, yielding a mean score of parental symptoms of $\operatorname{ADHD}(M=3.94, S D 1.80)$.

Informants' ratings of the child's activity levels in infancy. The Infant Behavior Questionnaire (IBQ; Rothbart, 1981) was completed by a subset of families at the 6-month assessment; the activity scale was used as a measure of the infant's gross motor activity. At least one informant completed this scale in 265 families (250 mothers, 207 fathers and 207 third informants) with good reliability across informants. The activity scale showed good internal consistency (alpha coefficients 
from .83 to .87 across informants). Mothers' reports were significantly correlated with fathers' reports, $r(204)=.53, p<.001$, and with the third informants' reports, $r$ $(194)=.33, p<.001$. Fathers' and third informants' reports were also significantly correlated, $r(168)=.29, p<.001$. Mplus7 (Muthén \& Muthén, 2012) was used to construct factor scores from the three informants' ratings. A confirmatory factor analysis using a Maximum Likelihood estimator with robust standard errors (MLR) to allow for deviations from normality resulted in factors scores, which were analogous to standardized scores (with mean and variance constrained to be 1 and 0 respectively). This factor explained $68 \%, 40 \%$ and $15 \%$ of the variance in mothers', fathers' and third informants' ratings respectively.

Measured activity. The infants' activity levels during the 6 months home visit were measured directly using an ActiGraph ActiTrainer (Manufacturing Technology Inc., MTI). The validity and reliability of this measure has been supported repeatedly (e.g., de Vries, Bakker, Hopman-Rock, Hirasing, \& van Mechelen, 2006; Eisenmann et al., 2004). The ActiGraph ActiTrainer had dimensions of $8.6 \mathrm{~cm}$ by $3.3 \mathrm{~cm}$ by $1.5 \mathrm{~cm}$ and weighed approximately 1.8 ounces. It was attached to the infants' upper left leg with a Velcro strap and recorded and stored accelerations per epoch (15 seconds). A 15 second epoch is recommended to allow for detection of normal human motion, and has previously been used in studies of preschool aged children (e.g., Pate, Almeida, McIver, Pfeiffer, \& Dowda, 2006). The data were downloaded via an integrated USB plug, stored in ASCII format and subsequently converted into a Microsoft Excel file with the Actilife Software. The data were cleaned and average accelerations per 30 seconds were calculated. 
Activity data were collected for a baseline period of 3 minutes, for a 3 minute 'attention' period when the infant explored an age-appropriate turtle toy that emits sound and light when manipulated, and for a restraint period of 30 seconds during which the infant was strapped in a car seat (adapted from Lab-TAB tasks; Goldsmith $\&$ Rothbart, 1999). Activity data across the three periods were positively and significantly correlated (Spearman's rho ranged from 0.25 to 0.15 , all $p<.05$ ). We thus estimated a measurement model considering activity in each period as indicators of an underlying latent dimension. Using Mplus 7 and an MLR estimator (to allow for non-normal distributions of the activity data), we were able to estimate factor scores for 266 infants who provided activity data in at least one period. The activity factor scores were transformed (square root transformation to allow for nonnormal distribution) and standardized for use in further analyses.

Self-regulation tasks in early childhood. During the individual assessment at the laboratory visit at a mean age of 33 months, children were presented with a battery of tasks, given in several random orders. The entire session was videorecorded by the experimenter for later observation and coding. The battery included four age-appropriate self-regulation tasks, all of which required the child to inhibit a prepotent response: the Tower of Cardiff planning task, the Raisin Task delay of gratification challenge, the Whisper Task inhibitory control task and the Big Bear, Little Bear nonverbal Stroop task (Figure 1). Two additional imitation tasks that were used to control for the children's testability and social learning abilities were also administered during the 25 minute testing session.

During the Tower of Cardiff task, the child was presented with a plastic pillar with plastic rings of various sizes; the pillar was narrower at the top than at the base, 
affording the stacking rings in a graduated order. The experimenter presented the child with an unusual order of rings and asked the child to copy that order on an empty pillar. Children were given two trials and the responses of the toddler were scored as ' 0 ' if no tower was built at all, ' 1 ' if the tower did not resemble the experimenter's tower and was not the conventional graduated tower, ' 2 ' if the child stacked the rings in graduated order; and ' 3 ' if the child copied the experimenter's tower exactly. A subsample of 57 participants $(25 \%)$ was used in order to establish inter-rater reliability. Perfect inter-rater reliability was found with an intra-class correlation of 1.00 .

The Raisin delay of gratification task (Kochanska, Murray, Jacques, Koenig, \& Vandegeest, 1996) was adapted from the original 'Snack Delay' task, in which a child was required to wait to retrieve an $\mathrm{M} \& \mathrm{M}$ from under a see-through cup (Kochanska et al., 1996). For this task a bell, a plastic box and three raisins were used (see Figure 1). The experimenter placed a raisin underneath a plastic box after which the child was instructed not to touch or eat the raisin until the bell rings. The child was given three trials. The child's response for each trial is scored as either 0 if the child eats the raisin before the experimenter rings the bell, 1 if the child touches the bell, box or raisin, but does not eat the raisin and 2 if the child does not eat the raisin and does not touch the bell, box or raisin during the trial. Total scores were corrected for the number of trials that the child completed. Good inter-rater reliability was found with an intra-class correlation of 0.96 .

The Whisper Task was adapted from a similar task used by Kochanska and colleagues, (1996). Children were presented with a toy farmyard, which was made up of a large plywood base, painted as a yard with a pond and vegetable patch (Figure 1 . 
The experimenter instructed the child to 'wake up' 10 plastic farm animals by naming each animal in turn, and whisper 'good morning' very softly to them. The child's response to each toy animal could be coded as 'shout', 'normal voice', 'low vocal sound' or 'whisper', which was scored as $0,1,2$ or 3 respectively. Good inter-rater reliability was found with an intra-class correlation of 0.98 .

The Big Bear, Little Bear task was adapted from the baby Stroop task (Hughes \& Ensor, 2005). Children were presented with a large picture of two bears, a big bear and a little bear. Two spoons (a big spoon and a small spoon) as well as two cups (a big cup and a small cup) were also used. The experimenter showed the child the large picture of two bears and explained to the child that Big Bear liked to use a small spoon and a small cup, whilst Little Bear prefers a big spoon and a big cup. The child was subsequently asked to place the four items with the correct bear during four trials (i.e. the small spoon and cup belonged to big bear and the large spoon and cup belonged to little bear). Children's responses could be coded as 'no response', 'conventional response' (incorrect) or 'correct response'. Scores ranged between 0 and 4, depending on how often the correct response was given. Good inter-rater reliability was found with an intraclass correlation of 0.99 .

Because each self-regulation task required conforming to the experimenter's modeling and/or instructions, the toddlers' social learning abilities were controlled for in a factor analysis using Mplus7, which was run on the scores from each selfregulatory task plus two imitation tasks administered as part of the battery. The analysis yielded three factors: imitation, behavioral regulation (the Raisin Task and Whispers Task), and cognitive flexibility (the Tower of Cardiff and Big Bear, Little Bear Task). In a follow-up analysis, the imitation factor was constrained to be 
orthogonal to the behavioral regulation factor, which yielded a better fit. Subsequent analyses were conducted on the behavioral regulation and cognitive flexibility factor scores derived from that final analysis. Behavior regulation and cognitive flexibility factor scores were available for 231 children who took part in laboratory tasks at a mean of 33 months. Self-regulation scores were transformed and standardized.

Informants' reports of ADHD symptoms in early childhood. Two different questionnaires were used to assess ADHD symptoms in early childhood. The Child Behavior Checklist (CBCL version 1.5 to 5 years; Achenbach \& Rescorla, 2000) was administered to parents and a third informant. The CBCL is a standardized questionnaire that includes 100 items that produce DSM-oriented scales, including the Attention Deficit/Hyperactive Problems scale, consisting of 6 items rated on a 3-point scale (mean $\alpha=.74$, range .73 to .75 across the three informants). Mplus 7 was used to create factor scores across informants at both time points, in a manner analogous to that used for the IBQ scores. The CBCL was completed by at least one informant in 254 families ( 240 mothers, 176 fathers and 182 third informants) at a mean of 36 months after the child's birth. Mothers' reports were significantly associated with fathers' reports, $r(168)=.42, p<.001$, and the third informants' reports, $r(172)=$ $.49, p<.001$, which were also significantly correlated with fathers' reports, $r(159)$ $=.31, p<.001$.

In addition, three ADHD-relevant items rated on a 3 point scale had been embedded into the Developmental Milestones Questionnaire given to the three informants at the mean age of 36 months: "Restless, overactive, cannot stay still for long," "Constantly fidgeting or squirming" and "Easily distracted, concentration wanders." The Milestones Questionnaire was completed by at least one informant in 
243 families (228 mothers, 178 fathers and 180 third informants). Mothers' reports were significantly correlated with fathers' reports, $r(165)=.51, p<.001$, and third informants' reports, $r(171)=.44, p<.001$, with fathers' and third informants' reports also significantly correlated, $r(153)=.36, p<.001$.

To maximize the number of participants contributing to the measure of ADHD symptoms in early childhood, data imputation drew on an identical Milestones Questionnaire that had been completed at the previous assessment at a mean age of 21 months; agreement between informants on the ADHD symptoms ranged from $r$ (186) $=.41, p<.001$ between mothers and fathers to $r(159)=.24, p=.002$ between fathers and third informants. At both ages, the three item scale from the Milestones Questionnaire showed good internal consistency (alpha coefficients between .72 and .78 across time point and informant). In cases where scores were missing on the Milestones Questionnaire at 36 months, SPSS linear regression was used to create predicted scores from the 21 month version of the questionnaire; the predicted scores produced by that regression analysis were then used to impute missing scores on the Milestones Questionnaire at 36 months.

Early childhood ADHD factor scores were then constructed using Mplus, drawing on both the CBCL DSM-relevant Inattention/Hyperactivity Problems and the Developmental Milestones Questionnaire. The factor analysis included 6 indicators and 3 latent factors (see Figure 1); the early childhood ADHD factor explained $54.6 \%$ and $79.8 \%$ of the variance in the latent CBCL and Developmental Milestones factor, respectively. Early childhood ADHD factor scores were computed for $N=286$ children. 
ADHD symptoms in middle childhood. At a mean of 7.0 years of age, the Child Behaviour Checklist (CBCL version 1.5 to 5 years; Achenbach \& Rescorla, 2000) was administered to parents, while the comparable Teacher Report Form was administered to teachers (TRF; Achenbach \& Rescorla, 2000). The items included in the TRF differed from the parent version of the CBCL Inattention/Hyperactive Problems scale and instead consisted of 13 items, which included: (1) “can't concentrate, can’t pay attention for long,” (2) “can’t sit still, restless, or hyperactive," (3) "can't stand waiting; wants everything now," (4) "demands must be met immediately," (5) "daydreams or gets lost in his/her thoughts," (6) "difficulty following directions," (7) "disturbs other children," (8) "gets into everything," (9) "fails to carry out assigned tasks," (10) "fidgets," (11) "quickly shifts from one activity to another," (12) “inattentive, easily distracted," and (13) “overactive."

The CBCL/TRF was completed in 283 families by at least one informant: 274 primary caregivers $(97 \%$ mothers, $2 \%$ fathers, and $1 \%$ grandmothers), 167 fathers as second informants, and 251 teachers). The internal consistency of this scale was confirmed with alpha coefficients of .80 for maternal, .72 for paternal and .91 for teacher's ratings. Mothers' reports on the CBCL $(M=3.43, S D 2.88)$ were significantly associated with fathers' reports $(M=3.73, S D 2.52), r(156)=.23, p<$ .01 , and with the teacher's reports on the TRF $(M=4.33, S D 5.45), r(138)=.49, p<$ .001 , but fathers' and teacher's reports were orthogonal, $r(157)=.05$.

Primary caregivers also completed the Conners 3AI-P index (Conners, 2008) in addition to the CBCL. This index contains the 10 items that best differentiate children with ADHD from healthy comparison children and are rated on a 4-point scale. Transposing rules need to be applied to the item responses after which a total 
raw score can be calculated. The Conners 3AI-P index was completed by 279 primary caregivers $(M=3.57, S D 5.41)$; the index showed good internal consistency $(\alpha=.88)$ and was significantly correlated with the CBCL ADHD scales completed by primary caregivers, $r(279)=.69, p<.001$, and fathers, $r(162)=.16, p=.04$. The Conners index was also significantly correlated with the TRF scale completed by teachers, $r$ $(245)=.44, p<.001)$.

Amsterdam Neuropsychological Tasks (ANT; De Sonneville, 1999). The Amsterdam Neuropsychological Tasks (ANT) are a computerised set of 38 tasks designed to measure executive function. The ANT is a well-validated and sensitive instrument to evaluate executive function in population-based samples (Brunnekeef et al., 2007). These tasks are used for both clinical and research purposes and can be administered to preschool-aged children, school-aged children, adolescents and adults (de Sonneville, 1999). The tasks show satisfactory to good validity, sensitivity and reliability (de Sonneville, 2005). Five tasks that were administered during the home visits at a mean of 7 years of age were included in the subsequent analyses.

Firstly, a Baseline Speed reaction time task was used to assess alertness/attention during a task that requires minimal cognitive effort. During 32 trials the child was asked to press a mouse-key as quickly as possible, when a fixation cross in the centre of the computer screen changes into a white square. Outcome measures were the mean reaction time, the within-subject standard deviation of the reaction time and the number of premature responses (i.e. when the child presses the mouse-key before the square has appeared).

Secondly, a Set Shifting task was used as a measure of attentional flexibility. This task consists of three parts. A coloured circle moves randomly to the right or left 
of a horizontal bar in the centre of the computer screen. During Part 1 the child is asked to make compatible response, by pressing the mouse-key on the same side as the direction of movement of the circle. A prepotent response is thereby established during this condition. During Part 2 the child is required to make incompatible responses, by pressing the mouse-key on the side opposite to the direction of the movement of the circle. The incompatible condition thus requires inhibition of prepotent responses. A measure of response inhibition was calculated as the difference between children's mean reaction time speeds between the incompatible (part 2) and compatible (part 1) conditions.

Thirdly, a Pursuit task was included as a measure of eye-hand coordination, fine motor control and sustained attention. During this task the child is required to continuously track a target star that moves randomly on the screen for five minutes, by moving the computer mouse. Sustained attention was measured by computing the difference between the mean distance $(\mathrm{mm})$ from the star in the first 30 seconds, as compared to the last 30 seconds, with negative scores indicating lower sustained attention.

The fourth task consisted of a Visuospatial Memory task, designed to measure working memory. During this task 9 circles positioned on a $3 \times 3$ matrix are displayed on the computer screen. After a beep signal an animation is run in which a finger points at a number of circles. During 24 trials the child is required to point out the same circles in the same order by clicking them with the mouse. The measure of working memory was the number of correctly identified circles in the correct order. Finally, a Delay Frustration task was included as a measure of frustration tolerance. This consist of a simple task during which the child is required to select an 
image that matches a target image in either colour or shape, by clicking the correct image with the computer mouse. Once the correct image is clicked, the next trial commences (37 normal delay trials). However, the task is designed to randomly delay the onset of the next trial during 8 short delay trials (lasting 2-9 secs) and 10 long delay trials that always last 16 seconds. The child is instructed prior to the start of the task with the following remark from the child tester: "We have noticed that the computer doesn't always work for this task. Sometimes the computer doesn't seem to notice that you clicked an image and it is possible that you might have to press again to continue the task. Ok?" Outcome measures are the number of mouse-clicks during the long delay trials and the average duration during which the mouse-button is held down during the long delay trials.

Clinically significant diagnosis of ADHD in middle childhood. At age 7, the child's primary caregiver was interviewed using the Preschool Age Psychiatric Assessment (PAPA; Egger et al., 2006), which covers the full range of behaviors that are symptoms of psychopathological disorders of children under the age of eight years. Interviewers were trained by an official PAPA trainer and monitored throughout the data collection period. The data were sent to Duke University for independent analysis, using SAS algorithms designed to identify cases of DSM-IV disorders with clinical impairment. The PAPA has been used to estimate prevalence of ADHD in prior studies of epidemiological samples (e.g., Wichstrøm, Berg-Nielsen, Angold, Egger, Solheim, \& Sveen, 2012). In the present sample, 9.7\% of children met the DSM-IV criteria for ADHD with impairment (4.2\% of girls and $13.4 \%$ of boys).

\section{Plan of Analysis}


In initial analyses, correlations between the ADHD-relevant variables and directly measured behavior were examined at each age of assessment. These measures were also examined in relation to three key risk factors at each age: gender, family adversity, and parents' own history of ADHD. We then used Structural Equation Modelling (SEM) to test a path model of the longitudinal associations between infants' activity at 6 months, ADHD symptoms and self-regulation abilities in early childhood, and ADHD symptoms at 7 years. We hypothesized that activity levels in infancy, as reported by informants and measured by Actigraphs, could lead to increased ADHD symptoms and poorer self-regulation abilities in early childhood, which in turn would contribute to ADHD symptoms at 7 years (the outcome). ADHD symptoms and self-regulatory abilities in early childhood would thus be intervening factors in paths that link activity levels in infancy to ADHD symptoms at 7 years.

The outcome of ADHD symptoms at 7 years was estimated by a latent continuous variable that represented mothers', fathers', and teachers' reports as well as the principal caregiver's Conners questionnaire. To allow for correlations between the two questionnaires completed by the principal caregivers, we included an association between the error variances of these variables. We also included an association between the error variances of maternal and paternal reports to allow for their interdependence. This measurement model is represented schematically in the righthand side of Figure 2.

We tested the measurement model and the structural relationships between variables using the sem function of Stata 13 (Stata Corp, 2013). The model was estimated using Maximum Likelihood with missing values to allow estimation of parameters for all $N=321$ that had provided data on any of the variables collected in 
infancy, early, or later childhood. As well as estimating the direct, indirect and total effects of the predicting variables on the outcome, we also investigated the significance of specific indirect effects using nonlinear comparison commands available in Stata 13. These specific indirect effects involved pathways from activity at 6 months $\mathrm{ADHD}$ symptoms at 33 months $\mathrm{ADHD}$ symptoms at 7 years and from activity at 6 months Self-regulation at 33 months ADHD symptoms at 7 . In the models, residual variances of measures at each age were correlated. The model is represented in Figure 1 (together with estimated standardized coefficients). All the parameters were estimated controlling for covariates gender (dummy-coded as male), family adversity, and parental ADHD.

In a final analysis, we used logistic regression to examine the predictors of PAPA diagnoses of ADHD with evidence for clinical impairment at age 7. Diagnostic information was available for $84 \%$ of those assessed for activity levels at six months.

\section{Results}

\section{Infants' Activity Levels at Six Months}

Correlations across measures of activity. Means, standard deviations and intercorrelations for the informant-rated and directly measured activity variables at 6 months are reported in Table 2. Consistent individual differences were found for both rated and directly measured activity, as evidenced by significant agreement across informants and significant correlations in the Actigraph measures across the three tasks. However, the factor scores derived from the informants' ratings and the factor scores representing measured activity across tasks were orthogonal, $r(225)$ $=.05($ Table 3$)$. 
Risk factors. Associations between risk factors (gender, family adversity, and parental history of ADHD) and the rated and measured activity variables are reported in Table 4. The informants' reports on the IBQ activity scale were not associated with gender, family adversity, or parental ADHD. Boys displayed higher levels of directly measured activity, which was negatively associated with parental ADHD.

\section{ADHD Symptoms and Self-Regulation in Early Childhood \\ Correlations across rated and direct measures of children's behavior.}

Means, standard deviations, and intercorrelations for the CBCL ADHD symptoms factor score and the behavior regulation and cognitive flexibility factor scores are reported in Table 3. As expected, the children's ADHD symptoms in early childhood were inversely related to their self-regulatory abilities, both in terms of their behavioral regulation in the Raisin and Whisper tasks, $r(228)=-.22, p=.001$, and their cognitive flexibility in the Tower of Cardiff and Big Bear, Little Bear tasks, $r(228)=-.18, p=.006$.

Risk factors. At this age, girls showed better behavior regulation than did boys (see Table 4) but there were no gender differences in cognitive flexibility or in ADHD symptoms. Family adversity was unrelated to behavioral regulation and cognitive flexibility, but was positively associated with informants' reports of ADHD symptoms. Parents' own past symptoms of ADHD predicted their children's ADHD symptoms and poorer scores on the behavior regulation tasks.

\section{ADHD Symptoms and Executive Function Measures at 7 Years}

Correlations across measures. Associations between informants' reports of children's ADHD symptoms and ADHD-relevant measures of executive function are presented in Table 3. In general, parents agreed with teachers across measures and 
the informants' reports were corroborated by measured performance on the executive function tasks. The factor representing the parents' reports on the CBCL ADHD scale and the Conners Index was positively and significantly correlated with teachers' reports of ADHD symptoms on the TRF, $r=.45, p<.001$. ADHD symptoms as reported by parents and teachers were both positively correlated with the DSM-IV diagnosis of ADHD with clinical impairment, as determined by the PAPA interview.

All three measures of ADHD were correlated with ANT measures of the children's executive function abilities (see Table 5). In particular, all three outcome measures of ADHD at 7 years (parents' questionnaires, teachers' questionnaires and DSM-IV diagnosis) were significantly correlated with children's problems in sustained attention and working memory; reports provided by parents were also correlated with higher baseline speed.

Risk factors. Associations between the three key risk factors of gender, family adversity and parents' history of ADHD and the variables measured at age 7 are presented in Tables $4 \mathrm{a}$ and $4 \mathrm{~b}$. ADHD symptoms as reported by parents and teachers and the DSM-IV diagnosis of ADHD with impairment were significantly associated with all three risk factors. A slightly different pattern was seen with respect to the executive function measures. In comparison to boys, girls showed significantly better inhibitory control, sustained attention, and working memory; boys showed more frustration. Family adversity was associated with poorer working memory, but was not significantly associated with performance on the other tasks. Children whose parents had a history of ADHD showed more frustration and poorer working memory.

\section{Continuity of Individual Differences over Time}


Continuity from infancy to early childhood. Associations in informantrated and directly measured variables in infancy and early childhood are reported in Table 5 . Higher activity levels as reported by informants at six months significantly predicted ADHD symptoms at 36 months, $r(249)=.21, p=.001$. In contrast, none of the other IBQ temperament scales were significantly associated with ADHD symptoms at 36 months, coefficients ranging from $r=.02$ for the duration orienting scale to $r=.12$ for the distress to limitations scale.

Higher IBQ activity scores did not significantly predict the children's behavioral self-regulation on the Raisin Task or the Whisper Task; however, infants with higher activity levels were less likely to inhibit prepotent responses in cognitive tasks, as indicated by lower scores on the cognitive flexibility factor (the factor score derived from performance on the Tower of Cardiff and Big Bear Little Bear tasks). In contrast, directly measured activity in infancy did not predict these early childhood outcomes.

Continuity from early childhood to age 7. Associations in informants' reports and directly measured variables at the early and middle childhood assessments are reported in Table 4. Informants' CBCL ratings of ADHD symptoms in early childhood significantly predicted later ratings of ADHD symptoms by parents and teachers, $r(263)=.47, p<.001$ and $r(236)=.22, p=.001$, respectively. ADHD symptoms in early childhood were also associated with poorer working memory performance at age $7, r(237)=.21, p=.001$.

The measures of children's self-regulation in early childhood also predicted later outcomes (Table 5). The behavior regulation factor significantly predicted parents' and teachers' ratings of ADHD symptoms and the DSM-IV ADHD 
diagnosis; cognitive flexibility in early childhood also significantly predicted the clinical diagnosis. Those children who had shown better behavior regulation and cognitive flexibility in early childhood performed better on the working memory test at 7 years (Table 5).

\section{Prediction to ADHD Symptoms at Age 7}

The SEM model estimated, schematically represented in Figure 3, together with the standardized coefficients estimated, provided adequate fit $(\mathrm{CFI}=0.96$; RMSEA $=0.05)$. In Table 6 we report the direct, indirect and total effects estimated. Self-regulation scores in early childhood were reverse-coded to ensure higher scores indicated a more detrimental outcome across all the measures considered.

The results indicated significant direct associations between IBQ activity in early infancy and ADHD symptoms in early childhood: a 1 SD increase in interinformant IBQ scores was associated with a 0.19 SD increase in ADHD symptoms scores. ADHD symptoms in early childhood were, in turn, strongly related with the latent dimension representing severity of ADHD symptoms at 7 years: 1 SD increase in the ADHD score in early childhood was associated with a 0.42 SD increase in the ADHD score at 7 years.

There was no significant direct effect of self-regulation abilities in early childhood on ADHD scores at 7 years (standardized coefficient $=0.11$ ), and the model did not indicate a significant direct path from IBQ activity in early infancy to self-regulation at 33 months (standardized coefficient = -.02). Overall, the SEM model with covariates explained approximately $38 \%$ of the variability in ADHD scores at 7 years (see Figure 3). 
The results indicated a significant indirect path from IBQ activity in early infancy to ADHD scores at 7 years; a 1 SD increase in IBQ scores was associated with a 0.08 increase in the ADHD scores $(p=.01)$. The results confirm that activity reported by informants in early infancy predicted ADHD symptoms at 7 years through its relationship with intervening variables in early childhood. Decomposing the total effect of IBQ activity on ADHD scores at 7 years reveals that approximately $81 \%$ of this effect was indirect through intervening variables in early childhood.

Further analyses of the specific indirect effects revealed that virtually the totality of this effect was mediated through ADHD symptoms in early childhood. The nonlinear combination tests revealed that the coefficient of the pathway IBQ activity ADHD scores at 33 months ADHD scores at 7 years was $.08,95 \%$ CI .03 to $.13, p=.003$. The coefficient of the combination test of the pathway IBQ activity Self-Regulation at 33 months ADHD scores at 84 months was $-.001,95 \% C I-.01$ to $.01, p=.92$. Overall, the results suggest mediation whereby activity levels influenced symptoms of ADHD in early childhood, which in turn affect ADHD symptoms at 7 years.

\section{Prediction to Diagnosis of ADHD with Clinical Impairment at 7 Years}

The logistic regression analyses also revealed continuity over time (see Table 6). Even when controlling for the child's sex, socioeconomic adversity and parents' ADHD symptoms, ADHD symptoms in early childhood significantly predicted the DSM-IV diagnosis at age 7. When those covariates are taken into account, infants' activity levels at 6 months significantly predicted diagnoses of ADHD at age 7 . The contribution of infants' activity levels reduces to marginal significance when the early childhood symptoms of ADHD are added to the model, which further corroborates the 
findings from the SEM analyses, namely that ADHD-relevant symptoms consolidated from infancy to childhood (Table 7).

\section{Discussion}

\section{Summary of the Findings}

The aim of this study was to determine whether high activity level in infancy might predict later ADHD symptoms in early and middle childhood. This was done in the context of a prospective longitudinal study of firstborn children from a nationally representative community sample in the UK. Activity level—which on the surface bears a resemblance to one dimension of ADHD symptomatology, hyperactivitypredicted ADHD symptoms in early childhood and a diagnosis of ADHD with impairment at 7 years of age.

Previous research had found heightened activity levels in familiar but not novel situations, during afternoon testing rather than mornings (Dane et al., 2000), and under the condition of low rather than high environmental stimulation (Wood et al., 2009). Therefore high levels of consistency across different forms of measurement might not have been expected, but in our sample ratings of infants' activity showed consistency across different informants. Furthermore, direct measures of infants' activity similarly revealed consistent individual differences across three different tasks.

Despite this evidence for consistency across tasks and informants, the factor score derived from informants' ratings of high activity did not correlate with the factor score derived from the informants' reports. Rather, the two measures of activity in infancy appeared to be orthogonal. This is in line with other evidence for a lack of correlation between the IBQ Activity Scale and directly measured physical 
activity, particularly in younger infants (Eaton \& Dureski, 1986; Worobey, 2014). It was also noteworthy that gender differences were found in measured activity but not in the informants' reports, as had been reported in past research (Campbell \& Eaton, 1999). Taken together, these findings suggest that the activity measures derived from the Actigraphs and the temperament questionnaire, which both showed internal consistency across context, tapped into independent constructs.

Our findings suggest that the individual differences measured by the Actigraphs represented normal variation in physical activity during a brief series of qualitatively distinct and challenging events, experienced over a 10 minute period on a given day. In contrast, the informants' ratings represent an indication of infants' more general restlessness in response to daily routines such as eating, bathing and bedtime. The former may reveal differences in energy levels on a given day, whereas the latter may indicate a somewhat dysregulated response to everyday challenges.

This interpretation of informant-rated activity level as a measure of dysregulation is supported by the fact that the IBQ activity scale at 6 months predicted the children's later responses to experimental tasks in early and middle childhood, as well as to ADHD symptoms in early childhood and the diagnosis of ADHD at age 7. In particular, infants who had higher scores on the IBQ activity scale were less able to inhibit prepotent responses in early childhood and showed higher levels of frustration at age 7. An indirect pathway from early activity levels to later outcomes was mediated by ADHD symptoms in early childhood, which were in turn associated with contemporary difficulties in both behavioral and cognitive aspects of selfregulation. Our findings suggest that in future studies that test hypotheses about links between infant temperament and later ADHD symptoms (e.g., Galera et al., 2011; Nigg et al., 
2004), it would be useful to include measures of activity level at different ages across different contexts. It would also be of interest to examine the contribution of early activity levels to later ADHD symptoms in additional studies with genetically informative designs (Nikolas \& Burt, 2010).

\section{Limitations of the Findings}

Several limitations of this study need to be addressed. Firstly, the study was undertaken within the perspective of developmental psychopathology, using a longitudinal strategy to chart the emergence of clinical symptoms in a representative community sample. Most of the findings reported show small to medium effect sizes. Nonetheless, the findings that emerge from this and other community samples enable us to chart a developmental pathway toward clinically meaningful disorder; thus findings from such representative samples provide information about pathogenesis and complement the evidence provided by studies that focus on high risk or clinical samples. Our focus on firstborn children might also be seen as a limitation; many studies show no link between ADHD and birth order (e.g., Berger \& FelsenthalBerger, 2009), but one report suggests that firstborn children are more likely than laterborn children to present with ADHD in clinical samples (Masana Marin et al., 2014).

Secondly, the use of informants' reports of children's symptoms of ADHD can be considered a limitation, although efforts were made to include two parents and a third informant whenever possible at each stage of this study, including reports from teachers in middle childhood. Informants' reports correlated with ADHD-relevant measures of self-regulation and executive function in early and middle childhood. The clinical interview drew on the primary caregiver's report, but the PAPA interview 
requires a detailed report of particular events before a symptom is determined to be present, and diagnoses are made objectively through well-established algorithms.

What might also be seen as a limitation of our study is the lack of convergence between the two measures of activity level in infancy. The fact that the measured activity did not correlate with informants' reports in infancy might be seen both as a function of the brevity of the Actigraph assessment or a sign of bias in family members' reports. Given that these measures tend to converge in older infants (Worobey, 2014), it is possible that the informants simply get better at rating activity. Nonetheless, the fact that both measures revealed consistent individual differences across context refutes the notion that either measure was unreliable. Experimental tasks and informants' reports are subject to different sources of measurement error, which may attenuate associations between them. Rather, this finding suggests that activity levels in infancy deserve more systematic study. It would be useful to make a direct comparison, in a design where informants rate infants' activity over the same time period that it is directly measured. Far more extensive assessments of infants' physical activity, accompanied by age-appropriate tests of self-regulation, would be needed to confirm our speculation that the informant-based and Actigraphbased measures tap into conceptually distinct constructs.

A final limitation of the study is the fact that parents reported retrospectively on their own ADHD symptoms. It is possible that these reports underestimated the parents' past symptoms, due to issues with retrospective recall and the positive bias in the self-reports provided by children with ADHD (Owens, Goldfine, Evangelista, Hoza, \& Kaiser, 2007). In future work, it would be important to examine parents' current as well as past symptoms of ADHD. It is important to note, however, that the 32 
parents' reports of their own past symptoms predicted to directly observed measures of the child's behavior regulation, and so the intergenerational continuity from parent to child demonstrated here was not entirely reliant on shared methods variance.

Similarly, the informants' reports of the infant's activity level and the child's ADHD symptoms were associated with the observed measures of self-regulation in early childhood and executive function at age 7 , and so the evidence for continuities in development does not rely on a single form of assessment.

\section{Conclusions}

Despite the limitations we have noted, the findings from our study suggest that the developmental pathway to ADHD begins in the first months of life; this corroborates other recent research examining early predictors of ADHD. A high level of activity in infancy is not in itself a sign of pathology, but, coupled with selfregulatory problems that emerge in the toddler years, it may be a harbinger of later, clinically significant symptoms of ADHD. The question for future research is this: How does normal variation in a behavioral tendency like activity level consolidate into a symptom of disorder that impairs a child's life?

This is a fundamental question for investigators working within the domain of developmental psychopathology. Our evidence for continuity from activity level in response to daily challenges in infancy to clinically defined signs of disorder provides further support for the proposal by Sroufe and Rutter (1984) that it might be possible to identify the developmental origins of childhood disorders by examining their nonclinical antecedents. More thorough study of individual variation in activity and self-regulation in infancy in relation to risk and protective factors might aid in the detection of ADHD. It would also be useful to examine individual differences in 
activity level in the context of the new approach to diagnosis, the rDoC framework (e.g., Cuthbert, 2014); in particular, how does high activity level interact with the rDoC dimensions of positive and negative valence, which have been seen as relevance to the developmental pathway from early temperament to symptoms of ADHD (Nigg et al., 2004)? It would also be important to examine activity levels and early symptoms of ADHD in relation to parents' responses to the challenges of active, dysregulated infants.

Our analyses of a representative community sample have identified a pathway from activity levels in infancy toward later symptoms of ADHD; the mechanisms underlying that pathway now need to be investigated using different research designs. It might be especially useful to recruit a high risk sample of reasonable size in which to examine the progression of emerging symptoms from infancy to childhood, starting with more extensive assessment of activity level and self-regulation difficulties in the first year of life. Thus our findings in this community sample and the high risk research that follows on from them may ultimately inform early prevention and intervention strategies. 


\section{References}

Achenbach, T. M., \& Rescorla, L. A. (2000). Manual for the ASEBA Preschool Forms \& Profiles. Burlington, VT: University of Vermont, Research Center for Children, Youth, \& Families.

Auerbach, J.G., Landau, R., Berger, A., Arbelle, S., Faroy, M., \& Karplus, M. (2005) Neonatal behavior of infants at familial risk for ADHD. Infant Behavior and Development, 28, 220-224. Doi:10.1016/j.infbeh.2004.12.002 Barkley,

R.A. (1998). Attention-Deficit Hyperactivity Disorder: a handbook for diagnosis and treatment. New York: Guilford.

Becker, K., Blomeyer, D., El Faddagh, M., Esser, G., Schmidt, M.H., Banaschewski, T., \& Laucht, M. (2010). From regulatory problems in infancy to Attention Deficit/Hyperactivity Disorder in childhood: A moderating role for the dopamine D4 receptor gene? Journal of Pediatrics, 156, 798-803.e2. doi:10.1016/j.jpeds.2009.12.005

Berger, I., \& Felsenthal-Berger, N. (2009). Attention-deficit hyperactivity disorder (ADHD) and birth order. Journal of Child Neurology, 24, 692-696. doi:10.1177/0883073808330763

Brunnekreef, A. J., de Sonneville, L. M., Althaus, M., Minderaa, R. B., Oldehinkel, A. J., Verhulst, F. C., \& Ormel, J. (2007). Information processing profiles of internalizing and externalizing behavior problems: Evidence from a population-based sample of preadolescents. Journal of Child Psychology and Psychiatry, 48, 185-193. doi: 10.1111/j.1469-7610.2006.01695.x

Campbell, D.W., \& Eaton, W.O. (1999). Sex differences in the activity level of 
infants. Infant and Child Development, 8, 1-17. doi:

10.1002/(SICI)1522-7219(199903)

Conners, C.K. Conners ( $3^{\text {rd }}$ edition). Toronto, Canada: Multi-Health Systems.

Cortese, S., Kelly, C., Chabernaud, C., Proal, E., Di Martino, A., Milham, M.P., \& Castellanos, F.X. (2012). Towards systems neuroscience of ADHD: A meta-analysis of 55 fMRI studies. American Journal of Psychiatry, 169, 1038-1055. doi:10.1176/appi.ajp.2012.11101521

Cuthbert, B.N. (2014). The RDoC Framework: Facilitating transition from ICD/DSM to dimensional approaches that integrate neuroscience and psychopathology. World Psychiatry, 13, 28-35. doi: 10.1002/wps.20087

Dane, A.V., Schacher, R.J., \& Tannock, R. (2000). Does actigraphy differentiate ADHD Subtypes in a clinical research setting? Journal of the American Academy of Child and Adolescent Psychiatry, 39 (6), 752-760. doi.org/10.1097/00004583-200006000-00014

de Sonneville, L.M.J. (1999). Amsterdam Neuropsychological Tasks: a computer-aided assessment programme. In B.P.L.M. den Briner, P.J. Beek, A.N. Brand, S.J. Maarse, \& L.J.M. Mulder (Eds.), Cognitive ergonomics, clinical assessment and computer-assisted learning: Computers in psychology Vol. 6 (pp. 113-129). Lisse, Swets, \& Zeitlinger.

de Sonneville, L.M.J. (2005). Amsterdamse Neuropsychologische Taken: Wetenschappelijke en klinische toepassingen. Tijdschrift voor Neuropsychologie, 0, 27-41.

de Vries, S.I., Bakker, I., Hopman-Rock, M., Hirasing, R.A., \& van Mechelen, W. 
(2006). Clinimetric review of motion sensors in children and adolescents. Journal of Clinical Epidemiology, 5, 670-680.

doi:10.1016/j.jclinepi.2005.11.020

Eaton, W., \& Dureski, C.M. (1986). Parent and actometer measures of motor activity in the young infant. Infant Behavior and Development, 9, 383-393. doi:10.1016/0163-6383(86)90012-3

Egger, H.L., Erkanli, A., Keeler, G., Potts, E., Walter, B.K., \& Angold, A. (2006).Test-retest reliability of the Preschool Age Psychiatric Assessment (PAPA). Journal of the American Academy of Child and Adolescent Psychiatry, 45, 538 -549. doi:10.1097/01.chi.0000205705.71194.b8

Eisenmann, J.C., Strath, S.J., Shadrick, D., Rigsby, P., Hirsch, N., \& Jacobson, L. (2004). Validity of uniaxial accelerometry during activities of daily living in children. European Journal of Applied Physiology, 91, 259-263. doi:10.1007/s00421-003-0983-3

Elias, P., McKnight, A., \& Kinshott, G. (1999). SOC 2000: Redefining skill revision of the Standard Occupational Classification. Skills Task Force Research Paper 19. Nottingham, England: DfEE Publications.

Faraone, S.V., Biederman, J., Chen, W.J., Milberger, S., Warburton, R., \& Tsuang, M.T. (1995). Genetic heterogeneity in Attention-Deficit Hyperactivity Disorder (ADHD): Gender, psychiatric comorbidity and maternal ADHD. Journal of Abnormal Psychology, 104, 334-345. doi: 10.1037/0021-843X.104.2.334

Galera, C., et al. (2011). Early risk factors for hyperactivity-impulsivity and inattention trajectories from 17 months to 8 years. Archives of General 
Psychiatry, 68, 1267-1275. doi:10.1001/archgenpsychiatry.2011.13 Goldsmith, H.H., \& Rothbart, M.K. (1999). The Laboratory Temperament Assessment Battery. Unpublished manuscript, University of Oregon, Eugene.

Gurevitz, M., Geva, R., Varon, M., \& Leitner, Y. (2014). Early markers in infants and toddlers for development of ADHD. Journal of Attention Disorders, 18, 1422. doi: $10.1177 / 1087054712447858$

Hughes, C., \& Ensor, R. (2005). Executive function and theory of mind in 2-yearolds: A family affair? Developmental Neuropsychology, 28, 645-668. DOI: $10.1207 / \mathrm{s} 15326942 \operatorname{dn} 2802 \_5$

Kochanska, G., Murray, K., Jacques, T. Y., Koenig, A. L., \& Vandegeest, K. A. (1996). Inhibitory control in young children and its role in emerging internalization. Child Development, 67, 490-507. doi: 10.1111/j.14678624.1996.tb01747.x

Masana Marin, A., Lopez Seco, F., Marti Serrano, S., Acosta Garcia, S., Gaviria Gomez, A., \& Ney, I. (2014). Do firstborn children have an increased risk of ADHD? Journal of Attention Disorders, 18, 594-597. doi: $10.1177 / 1087054712445066$

Moreland, A.D., \& Dumas, J.E. (2008). Categorical and dimensional approaches to the measurement of disruptive behavior in the preschool years: A meta-analysis. Clinical Psychology Review, 28, 1059-1070. doi:10.1016/j.cpr.2008.03.001

Muthén, L.K., \& Muthén, B.O. (2012). Mplus user's guide ( $7^{\text {th }}$ ed.). Los Angeles, CA; Muthén \& Muthén.

Nigg, J.T. (2001). Is ADHD a disinhibitory disorder? Psychological Bulletin, 127, 
571-598. doi: 10.1037/0033-2909.127.5.571

Nigg, J.T., Goldsmith, H.H., \& Sachek, J. (2004). Temperament and Attention Deficit Hyperactivity Disorder: The development of a multiple pathway model. Journal of Clinical Child and Adolescent Psychology, 33, 42-53. doi: 10.1207/S15374424JCCP3301_5

Nikolas, M.A., \& Burt, S.A. (2010). Genetic and environmental influences on ADHD symptom dimensions of inattention and hyperactivity: A meta-analysis. Journal of Abnormal Psychology, 119, 1-17. DOI: 10.1037/A0018010

Olson, S.L., Bates, J.E., Sandy, J.M., \& Schilling, E.M. (2002). Early developmental precursors of impulsive and inattentive behavior: from infancy to middle childhood. Journal of Child Psychology and Psychiatry, 43, 435-447. doi: 10.1111/1469-7610.00035

Owens, J.S., Goldfine, M.E., Evangelista, N.M., Hoza, B., \& Kaiser, N.M. (2007). A critical review of self-perceptions and the positive illusory bias in children with ADHD. Clinical Child and Family Psychology Review, 10, 335-351. doi: $10.1007 / \mathrm{s} 10567-007-0027-3$

Pate, R.R., Almeida, M.J., McIver, K.L., Pfeiffer, K.A., \& Dowda, M. (2006). Validation and calibration of an accelerometer in preschool children. Obesity, 14, 2000-2006. doi: 10.1038/oby.2006.234

Porrino, L.P., Rapoport, J.L., Behar, D., Sceery, W., Ismond, D., \& Bunney, W.E. (1983). A naturalistic assessment of the motor activity of hyperactive boys: I. Comparison with normal controls. Archive of Genetic Psychology, 40, 681-687. doi:10.1001/archpsyc.1983.04390010091012

Reichenbach, L., Halperin, J.F. Sharma, V., \& Newcorn, J.H. (1992). Children's 
motor activity, reliability, and relationship to attention and behavior. Developmental Neuropsychology, 8, 87-97. doi:10.1080/87565649209540517

Rothbart, M. K. (1981). Measurement of temperament in infancy. Child Development, 52, 569-578. doi: 10.2307/1129176

Sroufe, L.A., \& Rutter, M. (1984). The domain of developmental psychopathology. Child Development, 55, 17-29. doi: 10.2307/1129832

Sullivan, E.L., Holton, K.F., Nousen, E.K., Barling, A.N., Sullivan, C.A., Propper, C.B., \& Nigg, J.T. (2015). Early identification of ADHD risk via infant temperament and emotion regulation: A pilot study. Journal of Child Psychology and Psychiatry, 56, 949-957. doi: 10.1111/jcpp.12426

Taylor, E. (2009). Developing ADHD. Journal of Child Psychology and Psychiatry, 50, 126-132. doi: 10.1111/j.1469-7610.2008.01999.x

Teicher, M.H., Ito, Y., Glod, C.A., \& Barber, N.I. (1996). Objective measurement of hyperactivity and attentional problems in ADHD. Journal of the American Academy of Child and Adolescent Psychiatry, 35, 334-342. doi: 10.1097/00004583-199603000-00015

Thomas, R., Sanders, S., Doust, J., Beller, E., \& Glasziou, P. (2015). Prevalence of Attention Deficit/Hyperactivity Disorder. Pediatrics, 135, 4. doi: $10.1542 /$ peds.2014-3482

Wichstrøm, L., Berg-Nielsen, T.S., Angold, A., Egger, H. L., Solheim, E., \& Sveen, T.H. (2012). Prevalence of psychiatric disorders in preschoolers. Journal of Child Psychiatry and Psychology, 53, 695-705. doi: $10.1111 / \mathrm{j} .1469-7610.2011 .02514 . \mathrm{x}$

Wood, A.C., Asherson, P., Rijsdijk, F., \& Kuntsi, J. (2009). Is overactivity a core 
Infant Activity Level and ADHD

feature in ADHD? Familial and receiver operating characteristic curve

analysis of mechanically assessed activity level. Journal of the American

Academy of Child and Adolescent Psychiatry, 48, 1023-1030.

doi: 10.1097/CHI.0b013e3181b54612

Worobey, J. (2014). Physical activity in infancy: developmental aspects,

measurement, and importance. The American Journal of Clinical Nutrition, 99, 729S-733S. doi: 10.3945/ajen.113.072397 
Infant Activity Level and ADHD

Table 1. Demographic characteristics of the full CCDS sample at the time of recruitment and at 7 years of age

\begin{tabular}{|c|c|c|}
\hline Variable & Pregnancy & 7 Years \\
\hline & $N=332$ & $N=286$ \\
\hline Mother's Age at Birth (Mean) & 28.15 & 28.39 \\
\hline Stable Partnerships & $90.4 \%$ & $90.2 \%$ \\
\hline Marital Status (\% married) & $50.3 \%$ & $51.0 \%$ \\
\hline Ethnicity (\% British or Irish) & $92.7 \%$ & $93.1 \%$ \\
\hline Occupation ( $\%$ middle class $)$ & $50.9 \%$ & $53.5 \%$ \\
\hline Mother's Basic Education & $78.3 \%$ & $78.7 \%$ \\
\hline Child's Gender (\% female) & $43.0 \%$ & $43.4 \%$ \\
\hline Socioeconomic Adversity Factor & 0 & -.03 \\
\hline
\end{tabular}


Infant Activity Level and ADHD

Table 2. Means, standard deviations, and Spearman's rho correlations between informant-reported and measured activity levels.

\begin{tabular}{|c|c|c|c|c|}
\hline & $\begin{array}{l}\text { 1. IBQ } \\
\text { Activity } \\
\text { Factor Score }\end{array}$ & $\begin{array}{l}\text { 2.Actigraph } \\
\text { Baseline }\end{array}$ & $\begin{array}{l}\text { 3.Actigraph } \\
\text { Attention Task }\end{array}$ & $\begin{array}{l}\text { 4.Actigraph } \\
\text { Restraint Task }\end{array}$ \\
\hline \multicolumn{5}{|c|}{ 然 } \\
\hline 2. & .05 & & & \\
\hline 3. & $.12^{+}$ & $.21 * *$ & & \\
\hline 4. & -.03 & $.25 * * *$ & $.11^{+}$ & \\
\hline Mean & .00 & 399.22 & 117.68 & 178.19 \\
\hline$S D$ & .84 & 365.82 & 169.48 & 260.03 \\
\hline$N$ & 265 & 265 & 266 & 261 \\
\hline${ }^{+} p<$ & $* p<.05$ & $<.01 * * *$ & 001 & \\
\hline
\end{tabular}




\section{Infant Activity Level and ADHD}

Table 3

\begin{tabular}{|c|c|c|c|c|c|c|}
\hline & $\begin{array}{l}\text { 1. IBQ Activity } \\
\text { factor Score at } 6 \\
\text { months }\end{array}$ & $\begin{array}{l}\text { 2. Recorded } \\
\text { Activity factor } \\
\text { score at } 6 \text { months }\end{array}$ & $\begin{array}{l}\text { 3. CBCL ADHD } \\
\text { symptoms factor } \\
\text { scores at } 33 \\
\text { months }\end{array}$ & $\begin{array}{l}\text { 4. Behavior } \\
\text { Regulation factor } \\
\text { score at } 33 \\
\text { months }\end{array}$ & $\begin{array}{l}\text { 5. Cognitive } \\
\text { flexibility factor } \\
\text { score at } 33 \text { months }\end{array}$ & $\begin{array}{l}\text { 6. ADHD factor } \\
\text { score at } 84 \text { months } \\
\text { ( } 7 \text { years) }\end{array}$ \\
\hline 2. & .05 & & & & & \\
\hline 3. & $.21 * * *$ & -.05 & & & & \\
\hline 4. & .0004 & .06 & $-.22 * * *$ & & & \\
\hline 5. & $-.14 *$ & .07 & $-.18 * *$ & $.31 * * *$ & & \\
\hline 6. & $.12+$ & .01 & $.49 * * *$ & $-.22 * *$ & $-.14^{*}$ & \\
\hline$M$ & 0 & 0 & 0 & 0 & 0 & 0 \\
\hline$S D$ & .84 & 1 & .83 & 1 & 1 & 1 \\
\hline Range & $-2.54,1.99$ & $-2.14,2.99$ & $-1.67,2.89$ & $-2.44,2.01$ & $-1.04,1.72$ & $-1.91,2.46$ \\
\hline$N$ & 265 & 266 & 286 & 231 & 231 & 285 \\
\hline
\end{tabular}


Infant Activity Level and ADHD

Table 4a

Correlations between risk factors and ADHD-relevant variables

\begin{tabular}{|c|c|c|c|c|c|c|c|}
\hline & $\begin{array}{l}\text { 1. IBQ } \\
\text { Activity } \\
\text { factor } 6 \\
\text { months }\end{array}$ & $\begin{array}{l}2 . \\
\text { Recorded } \\
\text { Activity } \\
\text { factor } 6 \\
\text { months }\end{array}$ & $\begin{array}{l}\text { 3. CBCL } \\
\text { ADHD } \\
\text { symptoms } \\
\text { factor } 36 \\
\text { months }\end{array}$ & $\begin{array}{l}\text { 4. Behavior } \\
\text { Regulation } \\
\text { factor score } \\
33 \text { months }\end{array}$ & $\begin{array}{l}\text { 5. Cognitive } \\
\text { flexibility } \\
\text { factor score } \\
\text { months }\end{array}$ & $\begin{array}{l}\text { 6. ADHD } \\
\text { factor } \\
\text { score at } 7 \\
\text { years }\end{array}$ & $\begin{array}{l}\text { 7. ADHD } \\
\text { Diagnoses } \\
\text { at } 7 \text { years }\end{array}$ \\
\hline Male & -.01 & $.14^{*}$ & .07 & $-.15^{*}$ & -.04 & $.19^{* *}$ & $.16^{* *}$ \\
\hline $\begin{array}{l}\text { Family } \\
\text { Adversity }\end{array}$ & .04 & -.05 & $.23 * * *$ & -.04 & -.10 & $.32 * * *$ & $.24 * * *$ \\
\hline $\begin{array}{l}\text { Parental } \\
\text { ADHD }\end{array}$ & .06 & $-.12 *$ & $.28 * * *$ & $-.20 * *$ & -.09 & $34 * * *$ & $.23 * * *$ \\
\hline
\end{tabular}

Table 4b. Correlations of risk factors with performance on ANT Executive Function Tests

$\begin{array}{llllll} & \text { Baseline Speed } & \text { Response Inhibition } & \text { Frustration } & \text { Sustained Attention } & \text { Working Memory } \\ \text { Male } & -.02 & -.13^{*} & .16^{*} & -.13^{*} & -.14^{*} \\ \text { Family Adversity } & .05 & -.06 & .05 & -.09 & -.26^{* *} \\ \text { Parental ADHD } & .04 & -.02 & .15^{*} & -.12+ & -.27^{* * *} \\ * p<.05 * * p<.01 & * * * p<.001 & & & \end{array}$




\section{Infant Activity Level and ADHD}

Table 5. Associations among measures of infant activity, ADHD symptoms, behavioral regulation and executive function.

\begin{tabular}{|c|c|c|c|c|c|c|c|c|c|c|c|c|}
\hline & 1 & 2 & 3 & 4 & 5 & 6 & 7 & 8 & 9 & 10 & 11 & 12 \\
\hline $\begin{array}{l}\text { 1.IBQ Activity } \\
6 \text { months }\end{array}$ & & & & & & & & & & & & \\
\hline $\begin{array}{l}2 \text { 2CBCL.ADHD } \\
\text { factor } 33 \\
\text { months }\end{array}$ & $.21^{* *}$ & & & & & & & & & & & \\
\hline $\begin{array}{l}\text { 3. Parents } \\
\text { ADHD Factor } \\
7 \text { years }\end{array}$ & $.14^{*}$ & $.47^{* * *}$ & & & & & & & & & & \\
\hline $\begin{array}{l}\text { 4. TRF ADHD } \\
7 \text { years }\end{array}$ & -.03 & $.22 * *$ & $.45^{* * *}$ & & & & & & & & & \\
\hline $\begin{array}{l}\text { 5. DSM IV } \\
\text { ADHD }\end{array}$ & $.14^{*}$ & $.29^{* * * *}$ & $.48^{* * *}$ & $.38^{* * *}$ & & & & & & & & \\
\hline $\begin{array}{l}\text { 6. Behavior } \\
\text { Regulation } 33 \\
\text { months }\end{array}$ & .02 & $-.17^{* *}$ & $-.16^{*}$ & $-.16^{*}$ & $-.15^{*}$ & & & & & & & \\
\hline $\begin{array}{l}\text { 7. Cognitive } \\
\text { Flexibility } 33 \\
\text { months }\end{array}$ & $-.14^{*}$ & $-.18^{* *}$ & $-.13+$ & -.04 & $-.20^{* *}$ & $.28^{* * *}$ & & & & & & \\
\hline $\begin{array}{l}\text { 8. ANT } \\
\text { Baseline Speed }\end{array}$ & $-.14^{*}$ & .05 & $.14 *$ & .08 & $.17^{* * *}$ & -.08 & .04 & & & & & \\
\hline $\begin{array}{l}\text { 9. ANT } \\
\text { Response } \\
\text { Inhibition }\end{array}$ & -.05 & .03 & .05 & .04 & .01 & .07 & .02 & $.19^{* * *}$ & & & & \\
\hline $\begin{array}{l}\text { 10. ANT } \\
\text { Frustration }\end{array}$ & $.16^{*}$ & .11 & .05 & .07 & .08 & .01 & .002 & -.05 & .03 & & & \\
\hline $\begin{array}{l}\text { 11. ANT } \\
\text { Sustained } \\
\text { Attention }\end{array}$ & .06 & -.09 & -.15 & $-/ 21^{* *}$ & $-.18^{* *}$ & .06 & .06 & $-.20^{* *}$ & -.003 & -.01 & & \\
\hline $\begin{array}{l}\text { 12. ANT } \\
\text { Working } \\
\text { Memory }\end{array}$ & .03 & $-.21^{* *}$ & $-.32^{* * * *}$ & $-.43^{* * * *}$ & $-.28^{* *}$ & $.20^{* *}$ & $.15^{*}$ & $-.34^{* * *}$ & $-.18^{* * *}$ & $-.14^{*}$ & $.33^{* * *}$ & \\
\hline $\begin{array}{c}M \\
S D\end{array}$ & $\begin{array}{r}0 \\
.84\end{array}$ & $\begin{array}{c}0 \\
, 83\end{array}$ & $\begin{array}{l}-.01 \\
.97\end{array}$ & $\begin{array}{c}4.33 \\
5.45\end{array}$ & $\begin{array}{l}.10 \\
.30\end{array}$ & $\begin{array}{c}0 \\
.66\end{array}$ & $\begin{array}{l}0 \\
.72\end{array}$ & $\begin{array}{l}445.15 \\
110.77\end{array}$ & $\begin{array}{l}309.42 \\
190.98\end{array}$ & $\begin{array}{l}173.45 \\
120.16\end{array}$ & $\begin{array}{r}-18.19 \\
37.25\end{array}$ & $\begin{array}{c}65.73 \\
18.48\end{array}$ \\
\hline
\end{tabular}

$+p<.10 * p<.05 * * p<.01 \quad{ }^{* * *} p<.001$ 
Table 6. Direct, Indirect, and Total effects estimated in the SEM path model.

IBQ activity on:

$\begin{array}{lrrrrr}\text { Male } & -0.04 & 0.10 & -0.35 & 0.729 & -0.02 \\ \text { Adversity } & 0.03 & 0.06 & 0.50 & 0.616 & 0.04 \\ \text { Parent ADHD } & 0.03 & 0.03 & 0.85 & 0.396 & 0.06 \\ \begin{array}{l}\text { Constant } \\ \text { HD 33 months on: }\end{array} & -0.07 & 0.14 & -0.52 & 0.605 & -0.09 \\ \text { IBQ activity } & & & & & \\ \text { Male } & 0.19 & 0.06 & \mathbf{3 . 3 1} & \mathbf{0 . 0 0 1} & \mathbf{0 . 1 9} \\ \text { Adversity } & 0.06 & 0.09 & 0.65 & 0.513 & 0.04 \\ \text { Parent ADHD } & 0.15 & 0.05 & \mathbf{2 . 8 6} & \mathbf{0 . 0 0 4} & \mathbf{0 . 1 8} \\ \text { Constant } & 0.10 & 0.03 & \mathbf{3 . 7 4} & \mathbf{0 . 0 0 0} & \mathbf{0 . 2 2} \\ & -0.40 & 0.12 & \mathbf{- 3 . 2 7} & \mathbf{0 . 0 0 1} & \mathbf{- 0 . 4 8}\end{array}$

Self-Regulation 33 months (reverse-coded) on:

$\begin{array}{lrrrrr}\text { IBQ activity } & -0.01 & 0.08 & -0.10 & 0.922 & -0.01 \\ \text { Male } & 0.27 & 0.13 & \mathbf{2 . 0 8} & \mathbf{0 . 0 3 8} & \mathbf{0 . 1 3} \\ \text { Adversity } & -0.03 & 0.08 & -0.45 & 0.649 & -0.03 \\ \text { Parent ADHD } & 0.11 & 0.04 & \mathbf{2 . 9 5} & \mathbf{0 . 0 0 3} & \mathbf{0 . 2 0} \\ \text { Constant } & 1.70 & 0.17 & \mathbf{1 0 . 1 9} & \mathbf{0 . 0 0 0} & \mathbf{1 . 7 0} \\ \text { HD 7 years on: } & & & & & \\ \text { IBQ activity } & 0.05 & 0.19 & 0.27 & 0.790 & 0.02 \\ \text { ADHD 33 mo } & 1.20 & 0.20 & \mathbf{6 . 0 3} & \mathbf{0 . 0 0 0} & \mathbf{0 . 4 2} \\ \text { Self-Reg.33 mo } & 0.27 & 0.17 & 1.56 & 0.120 & 0.11 \\ \text { Male } & 0.49 & 0.31 & 1.56 & 0.120 & 0.10 \\ \text { Adversity } & 0.31 & 0.16 & \mathbf{1 . 9 6} & \mathbf{0 . 0 5 0} & \mathbf{0 . 1 3} \\ \text { Parent ADHD } & 0.23 & 0.09 & \mathbf{2 . 6 8} & \mathbf{0 . 0 0 7} & \mathbf{0 . 1 7}\end{array}$

ADHD 7 years on:

$\begin{array}{llllll}\text { IBQ activity } & 0.22 & 0.08 & \mathbf{2 . 6 7} & \mathbf{0 . 0 1} & \mathbf{0 . 0 8}\end{array}$

ADHD 7 years on:

$\begin{array}{llllll}\text { IBQ activity } & 0.27 & 0.20 & 1.36 & 0.17 & 0.10\end{array}$

1.Maternal report

1.00 (constrained) .

0.84

constant

1.61

0.49

3.28

0.001

0.56

2.Mothers' Conner

$0.14 \quad 12.03$

0.000

0.77

constant

$0.87 \quad 0.53$

0.597

0.09

3.Paternal report

0.10

2.22

0.027

0.21

constant

0.27

12.23

0.000

1.33

4.Teachers' report

0.25

5.18

0.000

0.57

constant

0.83

2.44

0.015

0.37

Cov 1 \& 2

0.67

1.69

0.39

0.694

0.12

Cov $1 \& 3$

0.56

0.41

1.36

0.173

0.15 
Infant Activity Level and ADHD

Table 7. Parameters of nested logistic regressions of childhood and infancy predictors on ADHD diagnosis at 7 years. Parameters of predictors are based on the model that included all predictors (Block 3).

\begin{tabular}{|c|c|c|c|c|c|c|}
\hline & $\begin{array}{l}\text { Odds } \\
\text { Ratio }\end{array}$ & Std. Err. & $z$ & $p$ & $95 \%$ & CI \\
\hline \multicolumn{7}{|l|}{ Block 1} \\
\hline Male & 7.60 & 6.29 & $2.45^{*}$ & 0.014 & 1.50 & 38.47 \\
\hline Adversity & 1.06 & 0.33 & 0.18 & 0.857 & 0.57 & 1.96 \\
\hline $\begin{array}{l}\text { Parental } \\
\text { ADHD }\end{array}$ & 1.18 & 0.20 & 0.94 & 0.345 & 0.84 & 1.65 \\
\hline \multicolumn{7}{|c|}{ LR $\chi^{L}(3)=13.63 p=.004 ;$ Pseudo $\mathrm{R}^{L}=.1192$; Wald $\chi^{2}(3)=10.26, p=.017$} \\
\hline \multicolumn{7}{|l|}{ Block 2} \\
\hline $\begin{array}{l}\text { 6mo IBQ } \\
\text { Activity }\end{array}$ & 2.26 & 0.97 & $1.89+$ & 0.058 & .97 & 5.26 \\
\hline \multicolumn{7}{|c|}{ LR $\chi^{L}(4)=19.49 p=.001 ;$ Pseudo $\mathrm{R}^{2}=.1704 ;$ Wald $\chi^{2}(1)=5.10 p=.02$} \\
\hline \multicolumn{7}{|l|}{ Block 3} \\
\hline $\begin{array}{l}\text { ADHD } \\
\text { early } \\
\text { childhood }\end{array}$ & 2.74 & 1.04 & $2.66^{* *}$ & 0.008 & 1.30 & 5.76 \\
\hline Constant & .005 & 0.01 & $-4.43 * * *$ & 0.000 & .001 & 0.05 \\
\hline
\end{tabular}


Infant Activity Level and ADHD

Figure 1. Equipment used in self-regulatory tasks during the early childhood laboratory visit (Tower of Cardiff, Raisin Task, Whispers Task and Big Bear Little Bear Task)
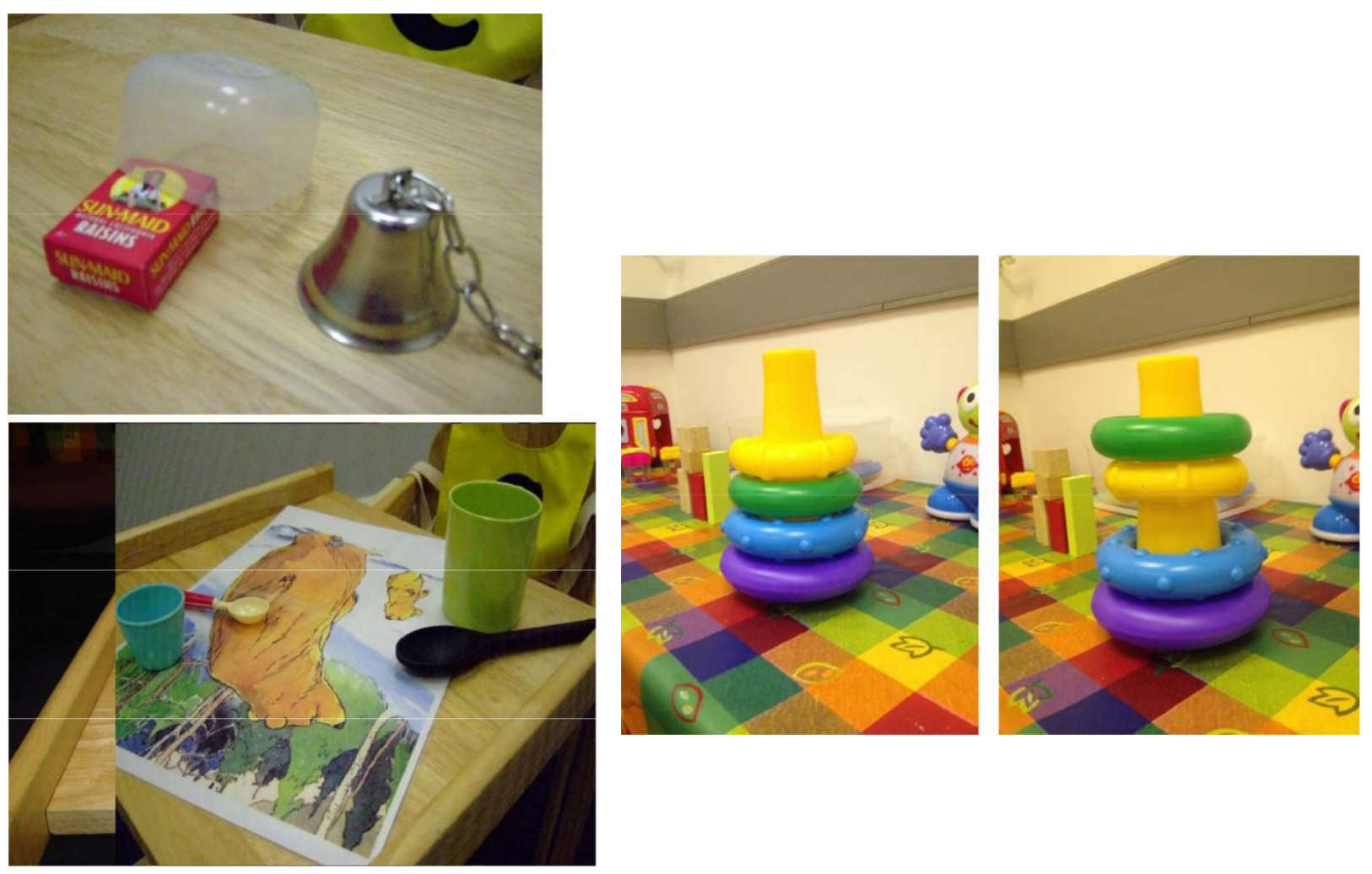
Infant Activity Level and ADHD

Figure 2. Measurement model for ADHD Factor Score in Early Childhood.

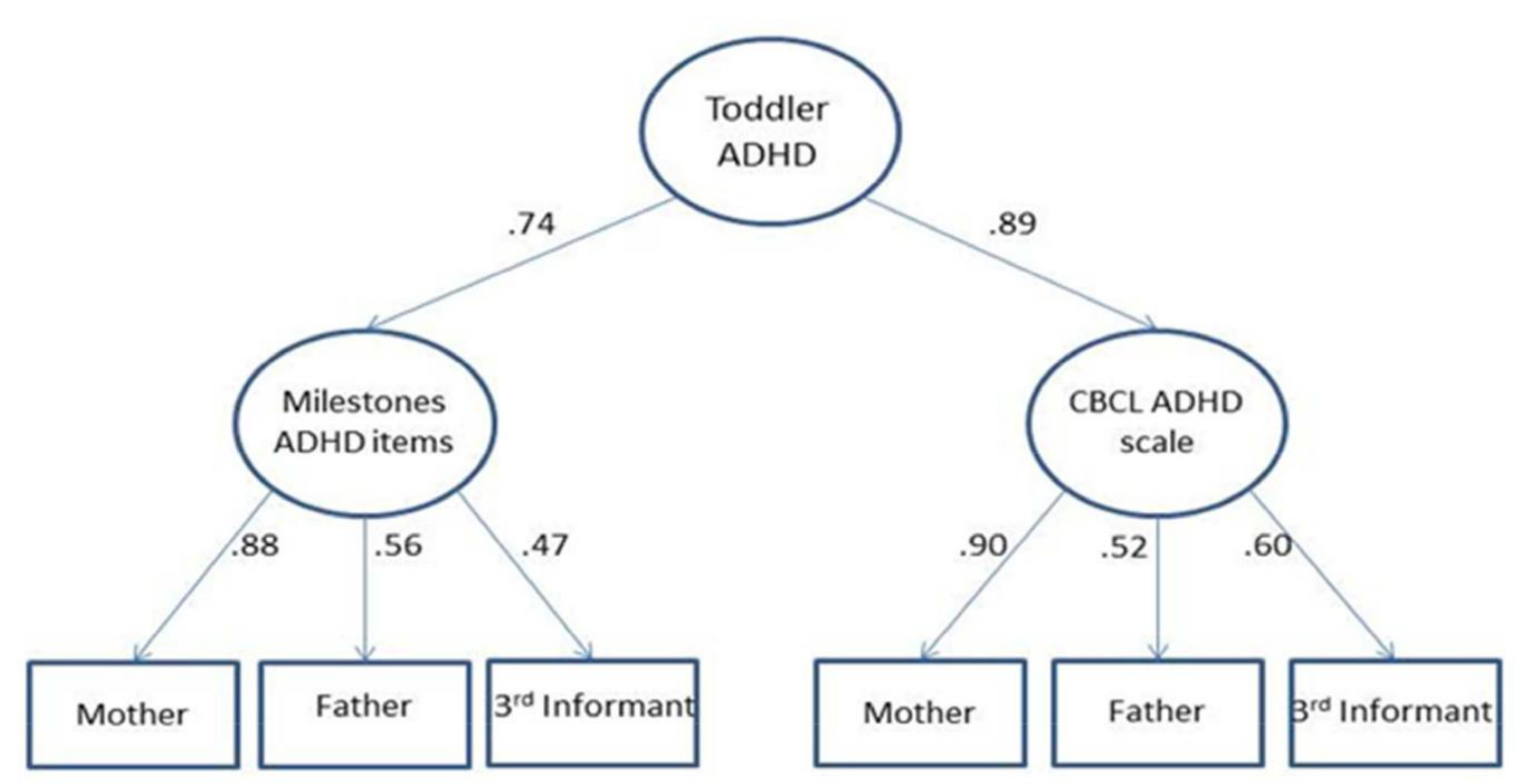


Figure 3. SEM model and standardized coefficients of pathways linking latent ADHD symptoms severity at 7 years to IBQ interinformant reports at 6 months.

6 Months 33 Months 84 Months
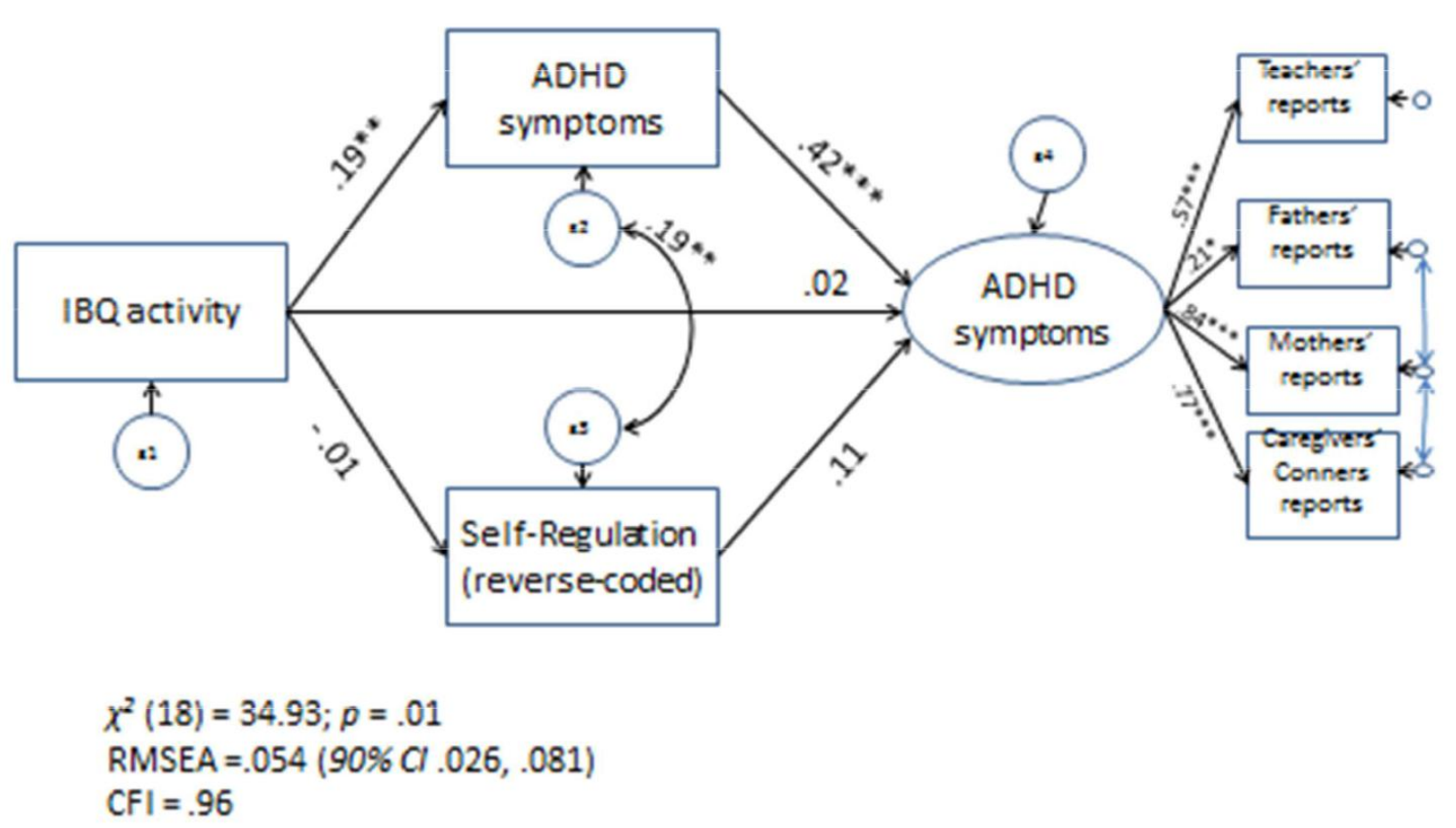